\title{
Effects of Fertilization Regimes on Grain Yields and Economic Returns of Pathum Thani 1 Rice Grown on Sapphaya Soil Series
}

\author{
Auraiwan ISUWAN* and Thanakrit KEAWARAM \\ Faculty of Animal Science and Agricultural Technology, Silpakorn University, Phetchaburi IT Campus, \\ Phetchaburi 76120, Thailand
}

('Corresponding author's e-mail: isuwan_a@silpakorn.edu)

Received: 30 April 2019, Revised: 22 July 2019, Accepted: 15 August 2019

\begin{abstract}
Fertilizer has been considered as one of the most important inputs, driving productivity and economic returns of rice farming systems. This study aimed to determine an optimized fertilizer rate to maximize grain yields, economic returns over fertilizer cost, and agronomic fertilizer nutrient use efficiency (ANUE) of Pathum Thani 1 rice grown on Sapphaya soil series. A completely randomized design with 5 replications was used. The treatments involved 4 fertilizer regimes: 1) no fertilizer application (control, C), 2) fertilizer application based on soil analysis (SSF) at a rate of 4-4.4-4 kg N$\mathrm{P}_{2} \mathrm{O}_{5}-\mathrm{K}_{2} \mathrm{O} /$ rai $(1 \mathrm{rai}=0.16$ hectare $), 3$ ) fertilizer application based on precision fertilizer management $(\mathrm{PF})$ at a rate of 7.86-2.52-13.39 kg/rai and 4) fertilizer application based on traditional farmer practice (F) at a rate of $15.5-5-0 \mathrm{~kg} / \mathrm{rai}$. The results uncovered that grain yields $(1,055 \mathrm{~kg} / \mathrm{rai})$ and economic return $(7,724 \mathrm{Baht} / \mathrm{rai})$ of rice received the $\mathrm{PF}$ treatment were significantly highest $(\mathrm{P}<0.05)$, which were approximately 78, 37, and $27 \%$ greater than those in the C, SSF, and F treatments, respectively. Similarly, the economic return of the PF was approximately 73, 46, and $35 \%$ superior to those in the C, $\mathrm{SSF}$, and F treatments, respectively. Moreover, ANUE (nitrogen and phosphorus) of rice received PF were greater $(\mathrm{P}<0.05)$ than other treatments. These results suggest that productivity and economic returns of Pathum Thani 1 rice grown on Sapphaya soil series can be optimized by applying fertilizer at a rate of 7.86-2.52-13.39 kg N- $\mathrm{P}_{2} \mathrm{O}_{5}-\mathrm{K}_{2} \mathrm{O} /$ rai.
\end{abstract}

Keywords: Fertilizer management, Nutrient use efficiency, Rice, Yield

\section{Introduction}

Fertilizer has been considered as one of the most important inputs in rice farming systems [1]. Many fertilizer management strategies and technologies (e.g., variable fertilizer management practice and split fertilizer management practice) have been developed to maximize the productivity and nutrient recovery efficiency of rice while minimizing the cost associated with fertilizers [2,3]. However, those strategies and technologies can be different in terms of their application practices and efficiency. For example, Zhao et al. [4] reported that increased events of nitrogen fertilizer application largely influence the production and nitrogen use efficiency of rice. Also, Banayo et al. [5] emphasized that the implementation of sitespecific fertilizer management (SSF) practice where total amounts of fertilizer use are achieved by accounting for existing nutrients in soils and brought-in nutrient supplies often results in increased numbers of panicles per hill, leading to increased rice yield. The SSF practice has generally been proven to support rice production, nutrient use efficiency, and economic returns superior to those in traditional farmer practice $(\mathbf{F})$ [3,5]. The fertilizer management based on the traditional farmer practice varies, depending on several constraint factors. A lack of updated knowledge is globally one of the most constraint factors of farmers. For instance, in China, about $50 \%$ of farmers use fertilizers either over- or under-requirements of plants [4]. Similarly, in Petchaburi province, more than $50 \%$ of farmers apply 
http://wjst.wu.ac.th

fertilizers by ignoring existing nutrients in soils and nutrient requirements of rice [6]. As a consequence, relatively lower production capacity, economic returns over fertilizer cost, and fertilizer nutrient use efficiency are unavoidable [3,5].

Alternatively, total fertilizer use can be calculated by accounting for nutrient exports (in form of grain and straw) and natural loss potentials (e.g. ammonia) of individual fertilizers, precision fertilizer management practice (PF) [7]. In practice, this approach can be combined with the split fertilizer management practice to maximize rice production and nutrient use efficiency as well as farm profits. However, this combined approach has not yet been evaluated with regards to its beneficial effects on productivity, nutrient use efficiency, and economic returns of rice.

Therefore, the present study aimed to determine and compare the productivity and economic returns over fertilizer cost of photoperiod insensitive rice (Pathum Thani 1) received either SSF or PF or F fertilizer practices.

\section{Materials and methods}

\section{Site and soil properties}

The study was conducted at a demonstration farm of the Faculty of Animal Science and Agricultural Technology, Silpakorn University, Petchaburi IT campus, about $250 \mathrm{~km}$ south of Bangkok, during May and November 2018. Soil properties (Fine-loamy, mixed, active nonacid, isohyperthermic Aquic (Fluvenntic) Haqlustepts) are present in Table 1. Generally, the soil was under Sapphaya soil series with mild acidity and medium fertility, although the concentrations of nitrogen and phosphorus were very low.

Table 1 Properties of the soil used in this experiment.

\begin{tabular}{llll}
\hline Properties of the soil & Methods & Soil analysis & Interpretation \\
\hline $\mathrm{pH}($ soil: water; $1: 1)$ & McLean $[8]$ & 5.83 & Mild acidity \\
Electrical conductivity $(\mathrm{dS} / \mathrm{cm})$ & Jackson [9] & 1.14 & Not salty \\
Organic matter $(\%)$ & Walkley [10]; FAO [11] & 1.74 & Medium \\
Total nitrogen $(\%)$ & Bremner and Mulvaney [12] & 0.09 & Very low \\
Available phosphorus $(\mathrm{mg} / \mathrm{kg})$ & Bray and Kurtz [13] & 4.60 & Very low \\
Exchangeable potassium $(\mathrm{mg} / \mathrm{kg})$ & Peech et al. $[14]$ & 127.30 & High \\
Exchangeable calcium $(\mathrm{mg} / \mathrm{kg})$ & Peech et al. $[14]$ & 510.27 & Medium \\
Exchangeable magnesium $(\mathrm{mg} / \mathrm{kg})$ & Peech et al. [14] & 175.76 & Medium \\
\hline
\end{tabular}

\section{Experimental design}

A completely randomized design with 5 replications was used. The treatments involved 4 different fertilization regimes: (1) no fertilization (control, C), (2) fertilizer use based on soil analysis (site-specific fertilizer management, SSF) of 4-4-4 kg N- $\mathrm{P}_{2} \mathrm{O}_{5}-\mathrm{K}_{2} \mathrm{O} / \mathrm{rai}(1 \mathrm{rai}=0.16$ hectare $)$ or equivalent to $4.96 \mathrm{~kg}$ of 46-0-0 (urea), $9.57 \mathrm{~kg}$ of $18-46-0$ (diammonium phosphate) and $8.7 \mathrm{~kg}$ of $0-0-60$ (potassium chloride), (3) fertilizer use based on estimated nutrients exports (precision fertilizer management, PF) of $7.86-2.52-13.39 \mathrm{~kg} \mathrm{~N}-\mathrm{P}_{2} \mathrm{O}_{5}-\mathrm{K}_{2} \mathrm{O} /$ rai or equivalent to $14.93 \mathrm{~kg}$ of $46-0-0$ (urea), $5.48 \mathrm{~kg}$ of $18-46-0$ (diammonium phosphate) and $22.32 \mathrm{~kg}$ of $0-0-60$ (potassium chloride), and (4) fertilizer use based on traditional farmer practice $(\mathrm{F})$ of $15.5-5-0 \mathrm{~kg} \mathrm{~N}-\mathrm{P}_{2} \mathrm{O}_{5}-\mathrm{K}_{2} \mathrm{O} /$ rai or equivalent to $28.35 \mathrm{~kg}$ of $46-0-0$ (urea), $10.87 \mathrm{~kg}$ of 18-46-0 (diammonium phosphate) and $0.0 \mathrm{~kg}$ of 0-0-60 (potassium chloride).

For the SSF treatment, soil samples were analyzed chemically (Table 1) and subject to compute individual fertilizer demands (nitrogen, phosphorus, and potassium) using the Soil Management Recommendation Software version 2.1: http://oss101.ldd.go.th. The software has been developed by the Department of Agriculture, Ministry of Agriculture and Cooperatives, Thailand. 
http://wjst.wu.ac.th

For the PF treatment, individual fertilizer demands were calculated by using estimated nutrient export data, where estimated amounts of grain and straw [6] and their nutrient contents [7] were multiplied. Additionally, in the calculation of demand for nitrogen fertilizer, a potential nitrogen loss as ammonia was accounted for, using a factor of 0.1 [15], while phosphorus and potassium losses were assumed to be zero.

For the F treatment, individual fertilizers were based on a survey study [16].

\section{Soil preparation and planting management}

The soils were collected to a depth of 0-30 cm, air-dried, and ground to pass through a $2 \mathrm{~mm}$ screen. Subsequently, 50-kg soil was weighed and transferred into a $50 \mathrm{~cm}$ diameter $\times 40 \mathrm{~cm}$ height pot. Pots were spaced $1 \mathrm{~m}$ from each other to prevent potential shades.

In each pot, 4 hills of three 20 -d old plantlets were transplanted with $25 \mathrm{~cm}$ spacing. Other general management practices such as irrigation and weeding have been described elsewhere [6].

The total amounts of nitrogen fertilizer were split into 2 equal portions. The first portion was applied together with phosphorus and potassium fertilizers at 30 days after transplanting. The second portion of nitrogen fertilizer was applied at 52 days after transplanting.

The water level was kept constant at $10 \mathrm{~cm}$ above the soil surface over an experimental period. It should be noted that the irrigated water used in the present study was derived solely from the surface water reservoir. Even though additional nutrients could be obtained from this source, we expected no significant influence on the performance of rice as all treatments were received similar amounts of irrigated water.

\section{Data computation and statistical analysis}

Grain yields were harvested at 110 days after transplanting. The yield was standardized to a $14 \%$ moisture content. Agronomic nutrient use efficiency (ANUE) was calculated according to Ladha et al. [17]: ANUE $=\left(\mathrm{Y}_{\mathrm{T}}-\mathrm{Y}_{\mathrm{O}}\right) / \mathrm{F}_{\mathrm{N}}$ where $\mathrm{Y}_{\mathrm{T}}$ is grain yield $(\mathrm{kg} / \mathrm{rai})$ of the treatment pots; $\mathrm{Y}_{\mathrm{O}}$ is grain yield (kg/rai) of the control pots and $\mathrm{F}_{\mathrm{N}}$ is the total amount of individual fertilizer use (kg/rai).

The economic return over fertilizer cost was computed as the total income (standardized yield $(\mathrm{kg})$ $\times$ grain price $(7.30 \mathrm{Baht} / \mathrm{kg}$ )) less the total fertilizer cost (urea: $12.40 \mathrm{Baht} / \mathrm{kg}$, diammonium phosphate: 21.60 Baht $/ \mathrm{kg}$ and potassium chloride: $17.80 \mathrm{Baht} / \mathrm{kg}$ ).

Data were statistically analyzed using Analysis of Variance (ANOVA) and means were compared using Duncan's Multiple Range Test.

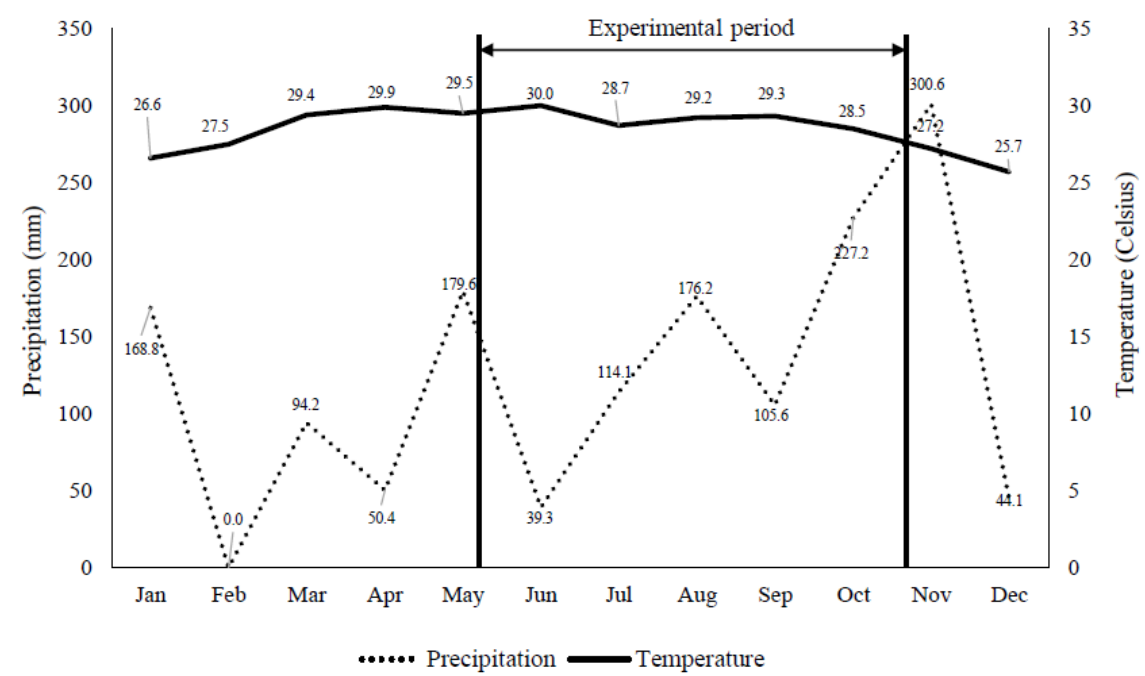

Figure 1 Monthly precipitation and temperatures over the experimental period. 
http://wjst.wu.ac.th

\section{Results and discussion}

The monthly precipitation and temperatures over the experimental period were within normal ranges in Petchaburi province, Thailand (Figure 1). Over the experimental period, the accumulated precipitation level was $1,143 \mathrm{~mm}$ and the average temperature was 28.9 Celsius.

\section{Yield and economic returns}

There were significant differences in grain yields and economic returns over the cost of fertilizers of the Pathum Thani 1 rice received different fertilization regimes (Table 2). The rice that received fertilizers (SSF, PF, and F) produced higher grain yields and economic returns than the control rice (C) $(\mathrm{P}<0.05)$. The $\mathrm{PF}$ rice demonstrated higher grain yield and economic returns when compared with the $\mathrm{SSF}$ and $\mathrm{F}$ rice $(\mathrm{P}<0.05)$. It should be noted that the $\mathrm{F}$ rice received approximately fourfold more nitrogen fertilizer and two-fold more phosphorus fertilizer, while the SSF rice received twofold less nitrogen fertilizer when compared to the PF rice. In general, Yoshida [18] and Dobermann and Fairhurst [19] summarized that imbalance of individual nutrients resulting from over-or under-fertilization can negatively affect productivity and nutrient use efficiency of rice. Furthermore, Fageria [20] reported that an optimized fertilization regime can help support the maximized genetic performance of rice, leading to increased plant growth, grain yields, and eventually economic returns [21]. Moreover, Banayo et al. [21] reported that the SSF rice in the Philippines generates more net income when compared with the F rice. In the present study, the PF rice produced about 78, 37, and $27 \%$ more grains and 73,46 and $35 \%$ more economic returns than those in the rice received the $\mathrm{C}, \mathrm{SSF}$, and F treatments, respectively. Besides, in our previous study [22] where the PF treatment has not yet been studied, the SSF rice usually resulted in better productivity and economic returns when compared with the $\mathrm{F}$ treatment. This is partly due to the over-fertilization of the $\mathrm{F}$ treatment, especially nitrogen fertilizers that can potentially lead to reduced nutrient use efficiency while increasing the cost of fertilizer use $[3,16]$.

Table 2 Yield and economic returns of rice grown in Sapphaya soil series and received different fertilization regimes.

\begin{tabular}{|c|c|c|c|c|c|c|}
\hline & \multicolumn{4}{|c|}{ Treatments } & \multirow[b]{2}{*}{ SEM } & \multirow[b]{2}{*}{ F-test } \\
\hline & $\begin{array}{c}C \\
(0-0-0)\end{array}$ & $\begin{array}{c}\text { SSF } \\
(4-4.4-4)\end{array}$ & $\begin{array}{c}\mathrm{PF} \\
(7.86-2.52-13.39)\end{array}$ & $\begin{array}{c}F \\
(15.5-5-0)\end{array}$ & & \\
\hline Grain yield (g/pot) & $133.60^{c}$ & $173.80^{b}$ & $237.20^{\mathrm{a}}$ & $187.40^{\mathrm{b}}$ & 7.56 & $* * *$ \\
\hline Grain yield (kg/rai") & $594.60^{\mathrm{c}}$ & $772.20^{\mathrm{b}}$ & $1,055.00^{\mathrm{a}}$ & $831.60^{\mathrm{b}}$ & 33.66 & $* * *$ \\
\hline $\begin{array}{l}\text { Returns over fertilizer } \\
\text { cost }\left(\mathrm{Baht}_{\left./ \mathrm{rai}^{\#}\right)}\right.\end{array}$ & $4,459.40^{\mathrm{c}}$ & $5,296.00^{\mathrm{b}}$ & $7,724.00^{\mathrm{a}}$ & $5,711.80^{\mathrm{b}}$ & 252.72 & $* * *$ \\
\hline
\end{tabular}

${ }^{\#} 1 \mathrm{rai}=0.16$ hectare, $* * *=$ significantly at $\mathrm{P}<0.001$ level.

Means with the same row followed by the same letter are not significantly different

\section{Fertilizer use efficiency}

The application of different fertilization regimes resulted in significant differences in agronomic nutrient use efficiency of rice (Table 3). The agronomic nitrogen use efficiency values of the SSF and PF rice were not different $(\mathrm{P}>0.05)$, but they were greater $(\mathrm{P}<0.05)$ than that in the $\mathrm{F}$ rice. The agronomic phosphorus use efficiency value of the PF rice was about fourfold better $(\mathrm{P}<0.05)$ than those in the SSF and $\mathrm{F}$ rice. In contrast, there was no difference in the agronomic potassium-use efficiency between the SSF and $\mathrm{PF}$ rice $(\mathrm{P}>0.05)$. It should be noted that no potassium fertilizer was applied in the $\mathrm{F}$ rice.

Generally, optimized fertilization practices can lead to maximized nutrient use efficiency [5,21]. In contrast, the increased use of fertilizers always results in a reduction in nutrient use efficiency [23]. However, in the current study, although the PF rice received a greater amount of nitrogen fertilizer 
http://wjst.wu.ac.th

(approximately twofold) than the SSF rice, an agronomic nitrogen use efficiency value of the PF rice remained comparable to the SSF rice. Nevertheless, the agronomic nitrogen use efficiency value of the $\mathrm{F}$ rice was lower $(\mathrm{P}<0.05)$ than those of the SSF and PF rice. This is due partly to over-fertilization where nitrogen fertilizer in the $\mathrm{F}$ rice was approximately twofold compared with the PF rice. In the tropics, Yoshida [18] reported that the agronomic nitrogen use efficiency of rice ranges from 15 to $25 \mathrm{~kg}$ of rice paddy per $\mathrm{kg}$ of fertilizer nitrogen applied. In the present study, the agronomic nitrogen use efficiency of the F rice was within this range. However, the SSF and PF rice had higher agronomic nitrogen use efficiency values than the above range which confirmed that the efficiency of rice farming can be improved substantially by using optimal fertilizer technologies.

It can be seen that, on the one hand, the phosphorus use efficiency value of the PF rice was significantly higher than other treatments (This is due possibly to the PF rice received the optimal rate of phosphorus fertilizer which can support maximized plant growth performance and productivity [24]), on the other hand, overuse of phosphorus fertilizers (as in the SSF and F treatments) led to a reduction in phosphorus use efficiency of rice (Table 3).

Again, in our previous study [22] where the PF treatment has not been evaluated, the SSF rice usually revealed better nitrogen use efficiency when compared with the F rice. This is generally due to over-fertilization in the farmer's traditional fertilization practice.

Overall, our findings indicated that nitrogen fertilizers at a rate of 4.0 to $7.86 \mathrm{~kg}$ of nitrogen/rai, phosphorus fertilizers at a rate of $2.52 \mathrm{~kg}$ of $\mathrm{P}_{2} \mathrm{O}_{5} /$ rai, and potassium fertilizers at a rate of $4 \mathrm{~kg}$ of $\mathrm{K}_{2} \mathrm{O} / \mathrm{rai}$ can be an optimal rate to maximize nutrient use efficiency of Pathum Thani 1 rice grown on Sapphaya soil series which contain a very low concentration of nitrogen and phosphorus.

Table 3 Agronomic nutrient use efficiency (ANUE) of Pathum Thani 1 rice grown on Sapphaya soil series and received different fertilization regimes.

\begin{tabular}{|c|c|c|c|c|c|}
\hline & \multicolumn{3}{|c|}{ Treatments } & \multirow[b]{2}{*}{ SEM } & \multirow[b]{2}{*}{ F-test } \\
\hline & $\begin{array}{c}\text { SSF } \\
(4.0-4.4 .0-4) \\
\end{array}$ & $\begin{array}{c}\text { PF } \\
(7.86-2.52-13.39)\end{array}$ & $\begin{array}{c}F \\
(15.5-5.0-0.0)\end{array}$ & & \\
\hline ANUE (kg grain yield/kg N) & $44.32^{\mathrm{a}}$ & $58.52^{\mathrm{a}}$ & $15.77^{b}$ & 5.48 & $* * *$ \\
\hline ANUE (kg grain yield/kg P) & $40.29^{\mathrm{b}}$ & $182.52^{\mathrm{a}}$ & $47.32^{\mathrm{b}}$ & 8.83 & $* * *$ \\
\hline ANUE ( $\mathrm{kg}$ grain yield/kg K) & 44.32 & 34.35 & $\mathrm{Na}$ & 6.07 & ns \\
\hline
\end{tabular}

$* * *=$ significantly at $\mathrm{p}<0.001$ level and $\mathrm{ns}=$ not significant

Means with the same row followed by the same letter are not significantly different.

na $=$ Not available. This was because potassium fertilizers were not used in this treatment.

\section{Conclusions}

Fertilization regimes largely influence rice productivity. An optimized fertilizer application can lead to maximized productivity and economic returns of rice. Taking into account nutrient exports and unavoidable fertilizer loss potentials can be a practical option for an effective fertilizer management practice in rice-growing systems. In the present study, it can be concluded that fertilizer application at a rate of 7.9-2.5-13.4 kg N- $\mathrm{P}_{2} \mathrm{O}_{5}-\mathrm{K}_{2} \mathrm{O}$ /rai potentially maximizes productivity and economic returns of Pathum Thani 1 rice grown on Supphaya soil series.

\section{Acknowledgments}

This research was financially supported by the 2016 Petchaburi Provincial Development Fund. 
http://wjst.wu.ac.th

\section{References}

[1] A Dobermann, C Witt, D Dawe, GC Gines, R Nagarajan, S Satawathananont, TT Son, PS Tan, GH Wang, NV Chien, VTK Thoa, CV Phung, P Stalin, P Muthukrishnan, V Ravi, M Babu, S Chatuporn, M Kongchum, Q Sun, R Fu, GC Simbahan and MAA Adviento. Site-specific nutrient management for intensive rice cropping systems in Asia. Field Crop. Res. 2002; 74, 37-66.

[2] C Witt, A Dobermann, S Abdulrachman, HC Gines, G Wang, R Nagarajan, S Satawatananont, TT Son, PS Tan, LV Tiem, GC Simbahan and DC Olk. Internal nutrient efficiencies of irrigated lowland rice in tropical and subtropical Asia. Field Crop. Res. 1999; 63, 113-38.

[3] S Peng, JR Buresh, J Huang, X Zhong, Y Zou, J Yang, G Wang, Y Liu, R Hu, Q Tang, K Cui, F Zhang and A Dobermann. Improving nitrogen fertilization in rice by site-specific $\mathrm{N}$ management. A review. Agron. Sustain. Dev. 2010; 30, 649-56.

[4] G Zhao, Y Miao, H Wang, M Su, M Fan, F Zhang, R Jiang, Z Zhang, C Liu, P Liu and D Ma. A preliminary precision rice management system for increasing both grain yield and nitrogen use efficiency. Field Crop. Res. 2013; 154, 23-30.

[5] NPMC Banayo, SM Haefele, NV Desamero and Y Kato. Site-specific nutrient management enhances sink size, a major yield constraint in rainfed lowland rice. Field Crops Res. 2018; 224, 769.

[6] A Isuwan. Effects of site-specific fertilization on yields and chemical properties of rice (Pathum Thani) grown in Sapphaya Soil Series (in Thai). Khon Kaen Agri. J. 2015; 43, 423-30.

[7] Haifa. Nutritional Recommendations for Rice.Available at: http://www.haifagroup.com/files/Guides/Rice.pdf.2018, accessed July 2016.

[8] EO Mclean. Soil pH and Lime Requirement. In: Page AL (Ed.). Methods of Soil Analysis, 1982, p. 199-224.

[9] ML Jackson. Soluble Salt Analysis for Soils and Water. Soil Chemical Analysis. Part 2: Chemical and Microbiological Properties. Prentice Hall, Englewood Cliffs, American Society of Agronomy Madison, 1958.

[10] AA Walkley. Critical examination of a rapid method for determining of organic carbon in soil: Effect of variation in digestion conditions and of inorganic soil constituents. Soil Sci. 1947; 63, 25163.

[11] FAO. The Euphrates Pilot Irrigation Project. Methods of Soil Analysis. Gadeb Soil Laboratory (A Laboratory Manual). Food and Agriculture Organization, Rome, 1974.

[12] JM Bremmer and CS Mulvaney. Nitrogen Total. In: Page AL (Ed.). Methods of Soil Analysis: Agron. NO. 9 Part 2: Chemical and Microbiological Properties. $2^{\text {nd }}$ ed. American Society of Agronomy, Madison, 1982, p. 595-624.

[13] RH Bray and LT Kurtz. Determination of total organic and available forms of phosphorus in soil. Soil Sci. 1945; 59, 39-45.

[14] M Peech, LT Alexander, LA Dean and JF Reed. Method of Soil Analysis for Soil Fertility Investigation. US Government Printing Office, Washington, 1947.

[15] Intergovernmental Panel on Climate Change (IPCC). Chapter 11: $\mathrm{N}_{2} \mathrm{O}$ emissions from managed soils, and $\mathrm{CO}_{2}$ emissions from lime and urea application. In: HS Eggleston, L Buendia, K Miwa, T Ngara and K Tanabe (Eds.). IPCC Guidelines for National Greenhouse Gas Inventories: Volume 4 Agriculture, Forestry and Other Land Use Global Environmental Strategies Kanagawa Japan, 2006.

[16] A Isuwan. Productivity of Phitsanulok-2 rice grown on Bang Len Soil Series and received soil analysis-based fertilizers (in Thai). J. Agri. Res. Ext. 2017; 34, 14-24.

[17] JK Ladha, H Pathak, T Krupnik, J Six and CV Kessel. Efficiency of fertilizer nitrogen in cereal production: Retrospects and prospects. Adv. Agron. 2005; 87, 85-156.

[18] S Yoshida. Fundamentals of Rice Crop Science. Los Baños, Philippines IRRI, 1981.

[19] A Doberman and T Fairhurst. Rice: Nutrient Management. Potash and Phosphate Institute of Canada, 2000

[20] NK Fageria. Yield physiology of rice. J. Plant Nutr. 2007; 30, 843-79. 
http://wjst.wu.ac.th

[21] NPMC Banayo, SM Haefele, NV Desamero and Y Kato. On-farm assessment of site-specific nutrient management for rainfed lowland rice in the Philippines. Field Crop. Res. 2018; 220, 88-96.

[22] T Keawaram and A Isuwan. Effects of fertilization regimes on yield and nutrient use efficiency of PathumThani 1 rice grown in Samut Prakan soil series (in Thai). In: Proceedings of the $3^{\text {rd }}$ National Conference, Ubonratchathani, Thailand, 2018, p. 274-9.

[23] EVSP Rao and R Prasad. Nitrogen leaching losses from conventional and new nitrogenous fertilizers in lowland rice culture. Plant Soil. 1980; 57, 383-92.

[24] G Nziguheba, S Zingore, J Kihara, R Merckx, S Njoroge, A Otinga, E Vandamme and B Vanlauwe. Phosphorus in smallholder farming systems of sub-Saharan Africa: Implications for agricultural intensification. Nutr. Cycl. Agroecosyst. 2016; 104, 321-40. 